\title{
FITOTERÁPICOS NA ODONTOLOGIA
}

\section{MEDICINES IN DENTIST HERBAL}

\author{
Camila de Melo Aleluia* \\ Viviane de Cássia Procópio* \\ Marília Terezinha Gonçalves Oliveira* \\ Paulo Guilherme Santos Furtado* \\ José Flávio Gabrich Giovannini** \\ Santuza Maria Souza de Mendonça***
}

\section{RESUMO}

\begin{abstract}
A Fitoterapia é conhecida como a ciência que estuda o efeito farmacológico de plantas com finalidade terapêutica. Os medicamentos fitoterápicos têm despertado o interesse de diversos centros de pesquisas e indústrias e o seu uso vem se intensificando. Pesquisas científicas já comprovaram a eficácia de inúmeros extratos vegetais com aplicabilidade na Medicina e na Odontologia. Dentre as principais plantas com ação terapêutica em afecções bucais estão o cravo-da-índia, a camomila, a romã, a malva, a unha-de-gato e a própolis. Essas plantas têm propriedades antimicrobianas, anti-inflamatórias, cicatrizantes e analgésicas. O presente trabalho tem como objetivo realizar uma revisão da literatura sobre a Fitoterapia com ênfase em suas aplicações na Odontologia.
\end{abstract}

Descritores: Fitoterapia • Odontologia • Medicamentos fitoterápicos • Plantas medicinais • Antibacterianos.

\section{ABSTRACT}

Phytotherapy is known as the science that studies the pharmacological effect of plants for therapeutic purposes. Herbal medicines have attracted the interest of several research centers and industries and their use has intensified. Scientific research has confirmed the efficacy of several plant extracts with applicability in Medicine and Dentistry. Among the main plants with therapeutic action in oral diseases are the clove, chamomile, pomegranate, mauve, the cat's claw and propolis. These plants have antimicrobial properties, anti-inflammatory, analgesic and healing. This paper aims to review the literature on Herbal Medicine with emphasis on their application in Dentistry.

Descriptors: Phytotherapy • Dentistry • Phytotherapeutic drugs • Plants, medicinal • Anti-Bacterial agents.

* Cirurgião Dentista, graduado pelo Curso de Odontologia do Centro Universitário Newton Paiva - BH/MG

** Cirurgião Dentista, graduado pela FO-UFMG. Mestre em Materiais Odontológicos pela FO-UFMG. Professor Adjunto do Curso de Odontologia do Centro Universitário Newton Paiva - BH/MG

*** Cirurgiã Dentista, graduada pela FO-UFMG. Mestre em Clínica Odontológica pela FO-UFMG. Doutoranda em Estomatologia pela FO-UFM. Professora Adjunto do Curso de Odontologia do Centro Universitário Newton Paiva - BH/MG 


\section{N T RO DUÇÃO}

Ao longo da história, as plantas têm sido utilizadas para tratamento de diversas enfermidades humanas. Essa prática contribuiu para melhoria da qualidade de vida e aumento das chances de sobrevivência do homem, assim como para a perpetuação do hábito de utilização das plantas como agente terapêutico ${ }^{1,2,3,4,5,6}$. A Fitoterapia é a ciência que estuda a utilização de plantas ou parte delas para tratamento de doenças que acometem a espécie humana ${ }^{1,3,7}$.

No início do século XX, o uso de plantas medicinais foi preterido por falta de embasamento científico, favorecendo a substituição dos medicamentos fitoterápicos pelos medicamentos alopáticos. Na década de 70, a Organização Mundial da Saúde (OMS) passou a incentivar o estudo científico das plantas medicinais, já que muitas das encontradas no Brasil ainda não possuíam eficácia científica comprovada ${ }^{1,2,3}$. Porém, a partir dos anos 80 e 90, observou-se um aumento expressivo no mercado mundial de medicamentos fitoterápicos, especialmente nos países industrializados ${ }^{8}$. Atualmente o uso de fitoterápicos tem se intensificado em vários países, especialmente no Brasil, que possui uma flora rica e diversa, com grande potencial para o desenvolvimento dessa ciência ${ }^{1,2,3,4,5,6}$.

Os medicamentos fitoterápicos, quando indicados e utilizados corretamente, só têm a contribuir para a saúde de quem os utiliza. Para isso, é imprescindível que ocorra previamente o diagnóstico preciso da doença ou identificação dos seus sinais e sintomas e a escolha da planta apropriada com sua adequada preparação ${ }^{9,10}$.

Apesar de a Fitoterapia já ser amplamente utilizada na área médica, sua aplicação na Odontologia ainda é modesta. A adição de plantas medicinais aos dentifrícios e enxaguantes bucais já é realidade, sendo que diversos extratos de plantas foram testados em estudos científicos com objetivo de avaliar seu potencial de redução da atividade de microrganismos comensais da cavidade bucal².

\section{METODOLOG IA}

Procedeu-se à busca de artigos científicos indexados nas bases de dados bi- bliográficos SciELO, MEDLINE e Lilacs, e publicados entre os anos de 2002 e 2011. Os descritores utilizados para a busca foram: Fitoterapia; Fitoterapia na Odontologia; Fitoterápicos; Planta medicinal e Atividade antimicrobiana. Priorizaram-se as publicações em línguas inglesa e portuguesa.

\section{REVISÃO DE LITERATURA}

Os medicamentos fitoterápicos são, de acordo com a Agência Nacional de Vigilância Sanitária (ANVISA), preparações obtidas empregando-se exclusivamente matéria-prima vegetal ativa. Podem estar disponíveis na forma sólida ou líquida ${ }^{1,3,7}$. Os extratos líquidos são normalmente preparados com etanol e água. Dentre eles podem-se citar xaropes, tinturas, gliceritos (extratos líquidos que utilizam o glicerol como solvente), óleos medicinais, alcoolaturas (produtos obtidos mediante a maceração de uma planta) e sucos de plantas. Para os extratos sólidos, os solventes são evaporados e processados até a secagem. Como exemplo destes, têm-se os grânulos, os comprimidos e as cápsulas ${ }^{8,11}$.

O tratamento com fitoterápicos tem como objetivo prevenir e curar doenças ou pelo menos minimizar seus sintomas. Apresenta vantagens como custo acessível à população e aos serviços públicos de saúde; fácil manuseio; grande disponibilidade de matéria-prima; excelente aceitação popular devido ao conhecimento dos efeitos terapêuticos das plantas e reações adversas mínimas, quando prescritos e administrados de forma correta. Possui também amplo espectro de ações farmacológicas que incluem atividades anti-inflamatória, antimicrobiana, ansiolítica, cicatrizante dentre outras $4,7,8,9,12,13,14,15$ $16,17,18,19$

Sabe-se, no entanto, que os medicamentos fitoterápicos também podem apresentar efeitos colaterais como toxicidade; alergias e hipersensibilidade, que variam desde uma dermatite temporária até um choque anafilático. Podem também estimular a motilidade uterina, provocando aborto ou tendo interação com outros medicamentos 4 , 8, 16, 17, 18 .

Para que um medicamento seja utilizado de forma segura, são necessárias in-
ALELUIA CM

PROCÓPIO VC

OLIVEIRA MTG

FURTADO PGS

GIOVANNINI JFG

MENDONÇA SMS

FITOTERÁPICOS

NA ODONTOLOGIA
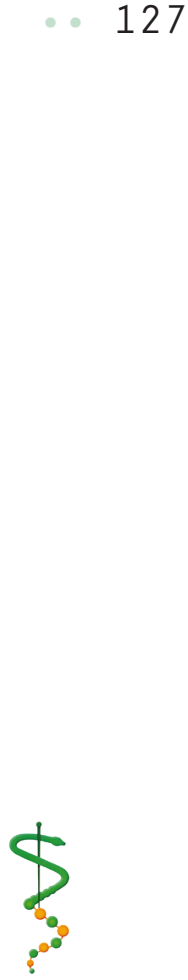

REV, ODONTOL. UNIV, CID. São PAULO

2015; $27(2)$ : 126 -

34, MAIO-AGO 
ALELUIA CM

PROCÓPIO VC

OLIVEIRA MTG

FURTADO PGS

GIOVANNINI JFG

MENDONÇA SMS

FITOTERÁPICOS NA ODONTOLOGIA

$128 \ldots$

REV. ODONTOL.

UNIV. CID. SÃO

PAULO

$2015 ; 27(2): 126-$

34, MAIO-AGO
I SSN 1983-5183

formações em relação às suas indicações, contraindicações e posologia. Entretanto, no comércio dos fitoterápicos essas informações são insuficientes, dificultando sua correta administração e, na maioria das vezes, são vendidos sem prescrição médica $^{15,20}$. Segundo Francisco ${ }^{16}$ (2010), são comuns os relatos de indivíduos que afirmam fazer a associação de plantas e medicamentos sintéticos sem orientação profissional. Essa associação entre drogas pode aumentar ou inibir o efeito terapêutico dos medicamentos sintéticos. Além disso, podem apresentar efeitos que se instalam em longo prazo e de forma assintomática, como os carcinogênicos, hepatotóxicos e nefrotóxicos. Assim sendo, recomenda-se o conhecimento dos seus princípios ativos, dos aspectos relacionados à qualidade da planta e da sua procedência, para que os mesmos possam ser usados com segurança ${ }^{16}$.

Embora o Brasil seja um país com grande diversidade de plantas medicinais e a literatura comprove a eficácia dos medicamentos desenvolvidos com base em seus extratos, ainda existem alguns obstáculos na produção de medicamentos fitoterápicos brasileiros. O primeiro deles é a escassez de leis que normatizam tanto a produção quanto a comercialização de fitoterápicos. Além disso, a maioria das plantas nativas não estão descritas em códigos oficiais como as farmacopéias. O país também necessita desenvolver pesquisas que comprovem a eficácias dessas plantas, assim como a ampliação dos serviços de farmacovigilância para que estejam aptos para avaliar os medicamentos produzidos $^{8,16}$.

O crescimento da Fitoterapia entre os programas preventivos e curativos tem estimulado pesquisas com o propósito de utilizar os extratos de diferentes plantas nas diversas especialidades odontológicas. O reconhecimento dessa ciência como uma prática integrativa e complementar à saúde bucal foi um grande passo para regulamentar a atuação dos cirurgiões-dentistas em uma área ainda pouco explorada. Apesar do medicamento natural ter boa aceitação popular no Brasil e apresentar boas perspectivas no mercado, estes só podem ser comercializados me- diante a realização de estudos laboratoriais e clínicos que comprovarem sua eficácia na área odontológica. Esse fato aguçou o interesse pela realização de pesquisas na área da Fitoterapia odontológica, com a proposta de desenvolvimento de medicamentos com menor toxicidade, melhor biocompatibilidade e que possam ser usados na terapêutica de odontalgias e afecções bucais ${ }^{16,21}$.

As afecções odontológicas são evidenciadas por sinais e sintomas característicos de diversas doenças, dentre elas as mais comuns são as lesões de cáries, gengivite, estomatite aftosa, herpes simples e candidose. Nesse contexto, a Fitoterapia surge como alternativa de interesse para a complementação do tratamento, sendo que já foram encontradas 132 espécies de plantas capazes de auxiliar no tratamento dessas afecções. Sabe-se, porém que a maioria dessas espécies não apresentam testes clínicos que comprovem sua eficácia, sendo embasadas apenas em pesquisas científicas laboratoriais ${ }^{4}$.

O cravo-da-índia, a camomila, a malva, a romã, a unha-de-gato e o própolis possuem ação consubstanciada por testes clínicos e laboratoriais e estão entre os fitoterápicos mais utilizados em Odontologia.

\section{Cravo-da-índia}

O cravo-da-índia (Syzygium aromaticun L.) cresce naturalmente na Indonésia e é cultivado em várias partes do mundo, incluindo o Brasil. É a partir dele que se extrai o eugenol, óleo essencial muito utilizado nos consultórios e com ação antimicrobiana. Além do seu uso na preparação dos produtos - cimentos, pastas, etc. - à base de óxido de zinco e eugenol, o cravo-da-Índia é utilizado pela população no tratamento de odontalgias, aftas, mau hálito e estomatites. Essa espécie possui propriedades medicinais de antissepsia, desinfecção e analgesia ${ }^{1,22,23}$.

\section{Camomila}

Também conhecida como Matricaria recutita $L .$, pertence à família Asteraceae. Os constituintes dessa planta incluem os terpenóides, alfa-bisabolol e os seus óxidos e azuleno, incluindo chamazulene. Essa planta medicinal vem sendo utilizada há um bom tempo como coadjuvante 
no tratamento de inflamações orais, por apresentar atividades anti-inflamatórias, cicatrizantes, sedativas e antimicrobianas. O seu efeito anti-inflamatório e antimicrobiano é atribuído ao óleo essencial azuleno que contém álcool sesquiterpeno, alfa-bisabolol, chamazulene e flavónoides. Os flavonoides agem inibindo a liberação de histamina, enquanto o bisabolol tem sido apresentado como promotor da formação de tecido de granulação na cicatrização de feridas. As possíveis formulações farmacêuticas de extrato de camomila são as preparações aquosas ${ }^{20}$ ou extratos alcoólicos. Todavia, essa planta pode interagir com anticoagulantes (como a varfarina) e aumentar o risco de sangramento, bem como intensificar ou até prolongar a ação depressora do sistema nervoso central quando usado concomitante a barbitúricos e outros sedativos. Sendo assim, o seu uso deve ser cauteloso $24,25,26,27$.

Albuquerque et al. ${ }^{24}$ (2010) avaliaram a atividade antimicrobiana, in vitro, do extrato da flor da camomila sobre microrganismos do biofilme dental. Os autores ainda compararam os resultados obtidos dos extratos hidroalcoólicos de camomila $(0,84 \mathrm{~g} / \mathrm{mL})$ sobre as linhagens bacterianas, com os resultados obtidos com a Clorexidina $0,12 \%$. As bactérias testadas foram Streptococcus mutans, S. mitis, S. sanguinis, S. sobrinus e Lactobacillus casei. Esse estudo mostrou que o referido fitoterápico apresentou atividade antimicrobiana contra todas as linhagens de bactérias testadas, porém com menor efetividade que a clorexidina a $0,12 \%$.

Duarte et al. ${ }^{25}$ (2011) realizaram um estudo, in vivo, que contava com uma amostra de 36 ratos. O objetivo desse estudo foi avaliar o efeito da camomila sobre a cicatrização de úlceras que foram induzidas nas línguas de ratos e estavam limitadas à mucosa. Os animais foram separados aleatoriamente em dois grupos, tratamento e controle. Os ratos do grupo de tratamento receberam aplicação tópica de $0,02 \mathrm{~mL}$ de extrato de camomila a $10 \%$, duas vezes por dia, com intervalo de 12 horas entre as aplicações. No grupo-controle, as feridas não foram tratadas. Ao final do experimento, os autores observaram que o grupo que foi tratado com a pomada de camomila apresentou melhores resultados em relação à epitelização e percentual de fibras colágenas após 10 dias. Contudo, não houve influência no grau da inflamação e tamanho da ferida.

\section{Romã}

A Punica granatum é uma pequena árvore nativa da Ásia. No Brasil, o fruto é comumente utilizado para o tratamento de infecções de garganta, tosse e febre devido às suas propriedades anti-inflamatórias e antibacterianas. A romã tem se mostrado eficaz no combate a bactérias gram-positivas e gram-negativas constituintes do biofilme bucal, uma vez que o tanino é o principal componente relacionado a essa atividade. Os taninos hidrolisáveis forma de complexos de alto peso molecular com proteínas solúveis - aumentam a lise bacteriana, assim como interferem no mecanismo de aderência bacteriana à superfície dos dentes ${ }^{28,29,30,31}$.

Em um estudo realizado por Pereira ${ }^{32}$ (1998) observou-se que o extrato hidroalcoólico do epicarpo da romã inibe a formação de placa supragengival com a mesma eficiência da clorexidina. A mesma autora ${ }^{33}$, no ano de 2002, realizou um estudo para avaliar a ação inibitória do extrato de romã sobre bactérias do biofilme dental, sendo estas: S. mitis, S. mutans, S. sanguis, S. sobrinus e L. casei. Todas as linhagens tiveram o seu crescimento inibido pela ação do extrato de romã, sendo S. sobrinus a mais sensível a ele. A romã é também utilizada no tratamento da periodontite em função de sua ação antioxidante e em estomatites como antisséptico. Segundo Sastravaha et al. ${ }^{34}$ (2005), Punica granatum e Centella asiatica são plantas medicinais que promovem regeneração tecidual e modulação da resposta imune.

\section{Malva}

A malva (Malva sylvestris) apresenta-se como uma planta herbácea, dispersa no continente europeu, africano e americano. Suas folhas, flores e raízes são utilizadas para fins farmacológicos. Esse vegetal é conhecido por suas propriedades anti-inflamatórias e antimicrobianas, determinadas pela presença de mucilagens, taninos, óleos essenciais, glicolipídios e flavonoides. Vem sendo testada no controle do crescimento de bactérias
ALELUIA CM

PROCÓPIO VC

OLIVEIRA MTG

FURTADO PGS

GIOVANNINI JFG

MENDONÇA SMS

Fitoterápicos

NA ODONTOLOGIA

- 129

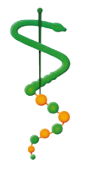

REV, ODONTOL.

UNIV, CID, SÃO

PAULO

$2015 ; 27(2): 126-$

34, MAIO-AGO 
ALELUIA CM

PROCÓPIO VC

OLIVEIRA MTG

FURTADO PGS

GIOVANNINI JFG

MENDONÇA SMS

FITOTERÁPICOS NA ODONTOLOGIA

$130 \ldots$

REV. ODONTOL.

UNIV. CID. SÃO

PAULO

$2015 ; 27(2): 126-$

34, MAIO-AGO
I SSN 1983-5183

presentes no biofilme dental. Também é indicada no tratamento de tosses, enfermidades de garganta e peito, devido ao fato de dissolver mucosidades ${ }^{4,35}$.

\section{Unha-de-gato}

A Unha-de-gato (Uncaria tomentosa) vem sendo utilizada ao longo dos séculos pela civilização indígena da floresta amazônica e de outras áreas tropicais das Américas do Sul e Central. Esse vegetal apresenta componentes como alcalóides oxíndoles, triterpenes, esteróides vegetais, compostos fenólicos, glicosídeos, tanino e flavonóides que podem ser relacionados com a sua atividade microbiana. Estudos realizados nos últimos anos comprovaram suas propriedades anti-inflamatórias, antineoplásicas, imunoestimulantes, antimicrobianas e antioxidantes ${ }^{9,13,36,37,38 .}$

Estudo realizado por Ccahuana-Vasquez et al. ${ }^{9}$ (2007) avaliou a atividade antimicrobiana de diferentes concentrações de Uncaria tomentosa sobre diferentes cepas de microrganismos de cavidades bucais humanas, tais como, Streptococcus mutans, Staphylococcus spp., Candida albicans, Enterobacteriaceae e Pseudomonas aeruginosa. Observou-se que concentrações de $4 \%$ e $5 \%$ inibiram $56 \%$ e $60 \%$ de S. mutans. Três por cento do extrato micropulverizado foi eficaz para inibir o crescimento de 8\% das Enterobacteriaceae. Nenhuma atividade da planta sobre o crescimento de $C$. albicans e $P$. aeruginosa foi observada nesse estudo.

Herrera et al. ${ }^{37}$ (2010) realizaram um estudo, in vitro, para avaliar a propriedade antimicrobiana da unha-de-gato perante os patógenos endodônticos Enterococcus faecalis, Staphylococcus aureus e Candida albicans, usando o método de difusão em ágar Mueller-Hinton. Foram utilizadas nesse estudo quatro substâncias auxiliares: o gel de clorexidina a $2 \%$, o gel de unha-de-gato a $2 \%$ (obtido a partir de um extrato liofilizado), o gel contendo clorexidina mais unha-de-gato a $2 \%$ e o gel de hidroxietilcelulose a $1 \%$ (como controle negativo). Os halos de inibição foram medidos após 24 horas a $37^{\circ} \mathrm{C}$ e as diferenças foram analisadas utilizando-se Análise de Variância Simples (ANOVA one-way). Os resultados mostraram que o diâmetro médio das zonas de inibição de crescimento microbiano de $2 \%$ do gel de clorexidina associado a unha-de-gato contra as cepas microbianas testadas variou de 21,7 a 33,3mm. Essa foi a substância mais eficaz contra E. faecalis e C. Albicans, seguida do gel de clorexidina e do gel unha-de-gato. Todos esses géis testados tiveram atividade antimicrobiana semelhante contra $S$. aureus $(\mathrm{P}>0,05)$. O gel de hidroxietilcelulose a $1 \%$ não teve efeito inibitório. Os autores concluíram que o gel de unha-de-gato a $2 \%$ inibe os patógenos endodônticos e que o efeito pode ser aumentado quando está combinado com clorexidina.

\section{Própolis}

A própolis é uma resina elaborada por abelhas (Apis mellifera) que coletam substâncias de rachaduras na casca das árvores, dos brotos e de outras partes das plantas. Essa resina é mastigada, enzimas salivares são adicionadas e o material, parcialmente digerido, é misturado com cera de abelha e utilizado por elas para selar furos nos seus favos de mel, suavizar as paredes internas e proteger a entrada contra os invasores. Sua coloração pode variar de amarelo-marrom a marrom escuro. É composta por 50 a $70 \%$ de bálsamos, 30 a $50 \%$ de óleos essenciais de cera, 5 a $10 \%$ de pólen e de outros componentes - aminoácidos, minerais, vitaminas $A$, complexo B e E, compostos fenólicos, flavonoides e aromáticos. Essa composição está intimamente relacionada com a ecologia da região onde é coletada $2,39,40,41$, ${ }^{42}$. Segundo Park et al. ${ }^{43}$ (2002), a própolis foi classificada em 12 tipos baseados em suas características físico-químicas. Contudo, apenas três grupos de espécies foram identificados no Brasil: cinco no sul (grupo 3), um no sudeste (grupo 12), e seis no nordeste (grupo 6). As propriedades terapêuticas da própolis são: antimicrobiana, anti-inflamatória, imunoestimulatória, cicatrizante e antisséptica ${ }^{40,44}$.

No Brasil, extratos de própolis estão disponíveis a partir de fontes comerciais e são usados como remédio popular para doenças infecciosas da cavidade bucal e orofaringe. Na Odontologia, a própolis é dispensada na forma de pasta de dente, antissépticos, pastilhas e pó, sendo utilizada no tratamento de várias afecções que acometem a cavidade bucal ${ }^{40,45}$. 
Estudos sugerem que os flavonoides e ácido cafeico presentes na própolis desempenham importante papel na redução da resposta inflamatória, ao inibirem a produção de ácido araquidônico e, por consequência, a síntese de prostaglandina. Além disso, ativam o timo, auxiliam o sistema imunitário através da promoção da atividade fagocítica, estimulam a imunidade celular e aumentam efeitos curativos sobre os tecidos epiteliais. A própolis também contém elementos como o ferro e o zinco que são importantes para a síntese de colágeno, além de estimularem vários sistemas enzimáticos e o metabolismo celular. Por isso é muito indicada na terapêutica pós-operatória, capeamento pulpar direto e agente indutor da formação de dentina reparadora e tecidos duros. Como um antimicrobiano, pode ser usada como irrigante intracanal, sendo que seu potencial é semelhante ao do hipoclorito de sódio; como agente cariostático; no tratamento da periodontite e candidoses ${ }^{40,41}$.

Em estudo de Feres et al. ${ }^{46}$ (2005), a própolis mostrou significativas propriedades antimicrobianas em amostras de saliva de indivíduos com periodonto saudável e doente, sugerindo que pode ser utilizada na inibição do crescimento microbiano bucal. Sonmez et al. ${ }^{47}$ (2005) avaliaram a atividade antimicrobiana de cinco amostras de própolis, coletadas em quatro diferentes regiões da Turquia e do Brasil, contra linhagens de anaeróbios. Todas as cepas foram sensíveis aos extratos etanólicos de própolis e valores de Concentração Inibitória Mínima ${ }^{35}$ variaram de 4-512 $\mu \mathrm{g} /$ $\mathrm{mL}$ Os autores concluíram que a própolis foi mais eficaz contra bactérias Gram-positivas anaeróbicas do que Gram-negativas, sendo que os principais compostos da própolis responsáveis por essa atividade foram flavonoides e o ácido cafeico. Apesar dos resultados apresentados mostrarem que a própolis pode ser uma solução viável para vários tratamentos, sejam eles odontológicos ou não, o seu uso deve ser cauteloso e com indicação de um especialista. Parolia et al. ${ }^{40}$ (2010) relatam que a própolis pode interagir com outras drogas, como dissulfiram (Antabuse ${ }^{\circledR}$ ) ou metronidazol $\left(\right.$ Flagyl $\left.^{\circledR}\right)$, levando a náuseas e vômitos. Pode ser, ainda, alergênica para algumas pessoas. Acredita-se que a principal substância relacionada às reações alérgicas é o ácido cafeico. Os principais sintomas da reação alérgica à própolis são aparecimento de erupções cutâneas, inchaço, coceira, lesões de psoríase na pele ou feridas na boca. Pessoas que possuem alergia ao pólen; com asma; grávidas ou que apresentam alergia à picada de abeIha podem desenvolver também reação alérgica à própolis ${ }^{40}$.

\section{CONCLUSÃO}

De acordo com a literatura revisada, o cravo-da-índia, a camomila, a malva, a romã, a unha-de-gato e a própolis possuem ação consubstanciada por testes clínicos e laboratoriais e estão entre os fitoterápicos mais utilizados em Odontologia. Possuem ação antimicrobiana, anti-inflamatória, cicatrizante, dentre outras. Estudos científicos comprovam a efetividade dos fitoterápicos e suas vantagens em relação aos medicamentos alopáticos, inclusive na Odontologia. O baixo custo dos medicamentos fitoterápicos os torna mais acessíveis à população. A possibilidade de possuir menos efeitos colaterais ou tóxicos e a grande aceitação popular motivam a produção de medicamentos fitoterápicos pela indústria farmacêutica. Entretanto, o seu desenvolvimento ainda é bastante complexo, envolvendo estudos químicos, farmacológicos e clínicos de longo prazo. Os fitoterápicos podem contribuir para tratamento e controle de várias doenças, podendo ser utilizados concomitantemente ou não com o uso de medicamentos alopáticos. É importante que o profissional da saúde conheça a ação farmacológica dos vários medicamentos fitoterápicos, bem como seus efeitos adversos e as contraindicações. Desde que bem indicados e administrados com consciência, eles devem e podem ser amplamente aplicados na Odontologia.
AleLUiA CM

PROCÓPIO VC

OLIVEIRA MTG

FURTADO PGS

GIOVANNINI JFG

MENDONÇA SMS

FITOTERÁPICOS

NA ODONTOLOGIA

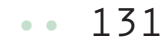

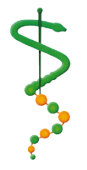


ALELUIA CM

PROCÓPIO VC OLIVEIRA MTG

FURTADO PGS

GIOVANNINI JFG

MENDONÇA SMS

FITOTERÁPICOS NA ODONTOLOGIA

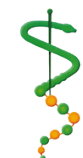

REV. ODONTOL.

UNIV. CID. SÃO

PAULO

$2015 ; 27(2): 126$ -

34, MAIO-AGO

\section{REFERÊNCIAS}

1. Assis C. Plantas medicinais na odontologia. Rev bras odontol 2009 jan-jun;66(1):72-5.

2. Molina FP, Majewski M, Perrela FA, Oliveira LD, Junqueira JC, Jorge AOC. Própolis, sálvia, calêndula e mamona: atividade antifúngica de extratos naturais sobre cepas de Candida albicans. Ciênc odontol Bras 2008 abr-jun;11(2):86-93.

3. Montes LV, Broseghini LP, Andreatta FS, Sant'anna MES, Neves VM, Silva AG. Evidências para o uso da óleo-resina de copaíba na cicatrização de ferida: uma revisão sistemática. Natureza online [Periódico on-line].2009; 7. Acesso em: Disponível em: www. naturezaonline.com.br/natureza/.../ pdf/02_monteslvetal_6167.pdf.

4. Oliveira FQ, Gobira B, Guimarães C, Batista J, Barreto M, Souza M. Espécies vegetais indicadas na odontologia. Rev bras farmacogn 2007 set;1 7(3):466-76.

5. Soares DGS, Oliveira CB, Drumond MRS, Padilha WWN. Atividade antibacteriana in vitro da tintura de aroeira (Schinusterebinthifolius) na descontaminação de escovas dentaiscontaminadas pelo s. mutans. Pesqui bras odontopediatria clín integr 2007 set-dez; 7(3):253-7.

6. Tomazzoni MI, Negrelle RRB, Centa ML. Fitoterapia popular: a busca instrumental enquanto prática terapêuta. Texto contexto - enferm 2006 mar;15(1):115-21.

7. Fernandes AV. Efeitos do uso tópico de Calendula officinalis na cicatrização de feridas em mucosa palatina: estudo histológico em ratos [Dissertação]. Araçatuba: Universidade Estadual Paulista; 2003.

8. Calixto JB. Medicamentos fitoterápicos. In: Yunes RA, Calixto JB. Plantas medicinais sobre a ótica da química medicinal moderna: métodos de estudo, fitoterápicos e fitofármacos, biotecnologia, patente. Chapecó: Argos; 2001. p. p.297-312.
9. Ccahuana-Vasquez RA, Santos SS, Koga-Ito CY, Jorge AO. Antimicrobial activity of Uncaria tomentosa against oral human pathogens. Braz Oral Res 2007 Jan-Mar;21(1):46-50.

10. Lima Júnior JF, Dimenstein M. A fitoterapia na saúde pública em Natal/RN: visão do odontólogo. Saude rev 2006 maio-ago;8(19):37-44.

11. Schulz V. Plantas medicinais, fitomedicamentos e fitoterapia. In: Schulz V, Hänsel R, Tyler VE. Fitoterapia racional: um guia de fitoterapia para as ciências da saúde. 4. ed. São Paulo: Manole; 2002. p. 1-40.

12. Almeida EC, Menezes H. Anti-inflammatory activity of propolis extracts: a review. J Venom Anim Toxins 2002 8(2):191-212.

13. Paiva LCA, Ribeiro RA, Pereira JV, Oliveira NMC. Avaliação clínica e laboratorial do gel da Uncaria tomentosa (Unha de Gato) sobre candidose oral. Rev bras farmacogn 2009 19(2a):4238.

14. Silva MSA, Silva MAR, Higino JS, Pereira MSV, Carvalho AAT. Atividade antimicrobiana e antiaderente in vitro do extrato de Rosmarinus officinalis Linn. sobre bactérias orais planctônicas. Rev bras farmacogn 2008 jun;18(2):236-40.

15. Toledo ACO, Hirata LL, Buffon MCM, Miguel MD, Miguel OG. Fitoterápicos: uma abordagem farmacotécnica. Rev Lecta 2003 jan-dez;21(1/2):7-13.

16. Francisco kMS. Fitoterapia: uma opção para o tratamento odontológico. Rev saúde 2010 4(1):18-24.

17. Lima Júnior JF, Vieira LB, Leite MJVF, Lima KC. O uso de fitoterápicos e a saúde bucal. Saúde rev 2005 7(16):117.

18. Pinheiro MLP, Andrade ED. Fitoterápicos como alternativa ao uso de medicamentos convencionais. Rev $A B O$ nac 2008 abr-maio;16(2):107-10. 
19. Veiga Junior VF, Pinto AC, Maciel MAM. Plantas medicinais: cura segura? Quím Nova 2005 jun;28(3):51928.

20. Farias MR, Schenkel EP, Bergold AM, Petrovick PR. O problema da qualidade de fitoterápicos. Cad farm 1985 $1(2): 73-82$.

21. Cechinel Filho V. Principais avanços e perspectivas na área de produtos naturais ativos: estudos desenvolvidos no NIQFAR/UNIVALI. Quím Nova 2000 out;23(5):680-5.

22. Daniel AN, Sartoretto SM, Schmidt G, Caparroz-Assef SM, Bersani-Amado CA, Cuman RKN. Anti-inflammatory and antinociceptive activities: a of eugenol essential oil in experimental animal models. Rev bras farmacogn 2009 mar;19(1b):212-7.

23. Paoli S, Giani TS, Presta GA, Pereira MO, Fonseca AS, Brandão-Neto J, et al. Effects of clove (Caryophyllus aromaticus L.) on the labeling of blood constituents with technetium-99m and on the morphology of red blood cells. Braz arch biol technol 2007 set;50( spe):175-82.

24. Albuquerque ACL, Pereira MSV, Pereira JV, Costa MRM, Pereira LF, Higino JS. Efeito antimicrobiano do extrato da Matricaria recutita Linn. (camomila) sobre microrganismos do biofilme dental. Pesq Bras Odontoped Clin Integr 2010 set-dez;10(3):451-5.

25. Duarte CM, Quirino MR, Patrocinio MC, Anbinder AL. Effects of Chamomilla recutita (L.) on oral wound healing in rats. Med Oral Patol Oral Cir Bucal 2011 Sep;16(6):e716-21.

26. Gupta V, Mittal P, Bansal P, Khokra SL, Kaushik D. Pharmacological potential of matricaria recutita: a review. Int J Pharm Sci Drug Res 2010 2(1):12-6.

27. Nicoletti MA, Oliveira-Junior MA. Principais interações no uso de medicamentos fitoterápicos. Infarma 2007 19(1/2):32-9.
28. Agra MF, Freitas PF, Barbosa-Filho JM. Synopsis of the plants known as medicinal and poisonous in Northeast of Brazil. Rev bras farmacogn 2007 mar;17(1):114-40.

29. Salgado AD, Maia JL, Pereira SL, de Lemos TL, Mota OM. Antiplaque and antigingivitis effects of a gel containing Punica granatum Linn extract: a double-blind clinical study in humans. J Appl Oral Sci 2006 Jun;14(3):162-6.

30. Vasconcelos LC, Sampaio FC, Sampaio MC, Pereira Mdo S, Higino JS, Peixoto $\mathrm{MH}$. Minimum inhibitory concentration of adherence of Punica granatum Linn (pomegranate) gel against S. mutans, S. mitis and C. albicans. Braz Dent J 2006 17(3):223-7.

31. Vasconcelos LC, Sampaio MC, Sampaio FC, Higino JS. Use of Punica granatum as an antifungal agent against candidosis associated with denture stomatitis. Mycoses 2003 Jun;46(56):192-6.

32. Pereira JV. Atividade antimicrobiana do extrato hidroalcolico da Punica granatum Linn: sobre microorganismos formadores de placa bacteriana [Dissertação]. João Pessoa: Universidade Federal da Paraíba; 1998.

33. Pereira JV. Estudos com o extrato da Punica granatum Linn. (Romã): efeito antimicrobiana in vitro avaliação clínica de um dentifrício sobre microrganismos do biofilme dental [Tese]. João Pessoa: Universidade Federal da Paraíba; 2002.

34. Sastravaha G, Gassmann G, Sangtherapitikul P, Grimm WD. Adjunctive periodontal treatment with Centella asiatica and Punica granatum extracts in supportive periodontal therapy. J Int Acad Periodontol 2005 Jul;7(3):70-9.

35. Drumond MRS, Castro RD, Almeida RVD, Pereira MdSV, Padilha WWN. Estudo comparativo in vitro da atividade antibacteriana de produtos fitoterápicos sobre bactérias cariogênicas. Pesqui bras odontopediatria clín integr 2004 jan-abr;4(1):33-8.
ALELUIA CM

PROCÓPIO VC

OLIVEIRA MTG

FURTADO PGS

GIOVANNINI JFG

MENDONÇA SMS

FITOTERÁPICOS NA ODONTOLOGIA

\section{3}

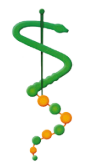

REV, ODONTOL.

UNIV, CID, SÃo

PAULO

$2015 ; 27(2)$ : $126-$

34, MAIO-AGO 
ALELUIA CM

PROCÓPIO VC

OLIVEIRA MTG

FURTADO PGS

GIOVANNINI JFG

MENDONÇA SMS

FITOTERÁPICOS NA ODONTOLOGIA

134 。

REV, ODONTOL

UNIV. CID, SÃO

PAULO

$2015 ; 27(2): 126-$

34, MAIO-AGO:
36. Heitzman ME, Neto CC, Winiarz E, Vaisberg AJ, Hammond GB. Ethnobotany, phytochemistry and pharmacology of Uncaria (Rubiaceae). Phytochemistry 2005 Jan;66(1):5-29.

37. Herrera DR, Tay LY, Rezende EC, Kozlowski VA, Jr., Santos EB. In vitro antimicrobial activity of phytotherapic Uncaria tomentosa against endodontic pathogens. J Oral Sci 2010 Sep;52(3):473-6.

38. De Martino L, Martinot JL, Franceschelli S, Leone A, Pizza C, De Feo V. Proapoptotic effect of Uncaria tomentosa extracts. J Ethnopharmacol 2006 Aug 11;107(1):91-4.

39. Fernandes Junior A, Balestrin EC, Betoni JE, Orsi Rde O, da Cunha Mde L, Montelli AC. Propolis: anti-Staphylococcus aureus activity and synergism with antimicrobial drugs. Mem Inst Oswaldo Cruz 2005 Aug;100(5):5636.

40. Parolia A, Thomas M, S, Kundabala M, Mohan M. Propolis and its potential uses in oral healt. Int J Med Sci 2010 jul;2(7):210-5.

41. Özan F, Sümer Z, Polat ZA, Er K, Özan $\ddot{U}$, Dener O. Effect of Mouthrinse Containing Propolis on Oral Microorganisms and Human Gingival Fibroblasts. Eur J Dent 2007 1(4):195-201.
42. Özen T, Kiliç A, Bedir O, Koru Ö, Sorkun K, Tanyuksel $M$, et al. In Vitro activity of turkish propolis samples against anaerobic bacteria causing oral cavity infections. Kafkas Univ Vet Fak Derg 2010 16(2):293-8.

43. Park YK, Alencar SM, Aguiar CL. Botanical origin and chemical composition of Brazilian propolis. J Agric Food Chem 2002 Apr 24;50(9):2502-6.

44. Barth OM, da Luz CFP. Palynological analysis of Brazilian red propolis samples. J Apicultural Res 2009 2009/01/01;48(3):181-8.

45. Dias JFG, Virtuoso S, Davet A, Cunico MM, Miguel MD, Miguel OG, et al. Atividade antibacteriana e antifúngica de extratos etanólicos de Aster lanceolatus Willd., Asteraceae. Rev bras farmacogn 2006 mar;16(1):83-7.

46. Feres M, Figueiredo LC, Barreto IM, Coelho MH, Araujo MW, Cortelli SC. In vitro antimicrobial activity of plant extracts and propolis in saliva samples of healthy and periodontally-involved subjects. J Int Acad Periodontol 2005 Jul;7(3):90-6.

47. Sonmez S, Kirilmaz L, Yucesoy $M$, Yucel B, Yilmaz B. The effect of bee propolis on oral pathogens and human gingival fibroblasts. J Ethnopharmacol 2005 Dec 1;102(3):371-6.

Recebido em 03/07/2015

Aceito em 15/10/2015 